\title{
Scattering of VHF radio waves from within an ice sheet containing the vertical-girdle-type ice fabric and anisotropic reflection boundaries
}

\author{
Shuji FUJitA, ${ }^{1 *}$ Kenichi MATSUOKA, ${ }^{2 \dagger}$ Hideo MAENO, ${ }^{3}$ Teruo FURUKAWA ${ }^{4}$ \\ ${ }^{1}$ Department of Applied Physics, Graduate School of Engineering, Hokkaido University, Sapporo 060-8628, Japan \\ E-mail:sfujita@pmg.nipr.ac.jp \\ ${ }^{2}$ Institute of Low Temperature Science, Hokkaido University, Sapporo 060-0819, Japan \\ ${ }^{3}$ Communications Research Laboratory, Nukui-kita 4-2-1, Koganei, Tokyo 184-8795, Japan \\ ${ }^{4}$ National Institute of Polar Research, Kaga, Itabashi-ku, Tokyo 173-8515, Japan
}

\begin{abstract}
We studied the scattering of radio waves off strata within the ice sheet at Mizuho station, Antarctica, to determine the most plausible scattering mechanisms at this location. We measured the effects of birefringence and anisotropic scattering boundaries on the return signal using the following set of experimental conditions: (1) co-polarization and cross-polarization antenna arrangements, (2) all orientations of the antenna system, (3) 60 and $179 \mathrm{MHz}$ frequencies, and (4) pulse lengths of 150-1000 ns. Analyses of the propagated radio waves suggested that the signal is dominated by anisotropic scattering boundaries at $179 \mathrm{MHz}$, but effects from birefringence also occurred. At depths of 250$750 \mathrm{~m}$, the scattering was stronger when the polarization plane was along the flowline. In contrast, at depths of about $900-1500 \mathrm{~m}$, scattering was stronger when the polarization plane was perpendicular to the flowline. We suggest that the scattering below about $250 \mathrm{~m}$ is related to a layered ice stratum of crystal-orientation fabrics with different types or different cluster strengths. Although our study was at a single site, similar remote measurements over wider regions should provide valuable information about the physical structure of this vast ice sheet.
\end{abstract}

\section{INTRODUGTION}

Understanding the physical structure of the Antarctic ice sheet is important for determining how this huge ice mass responded to past climate change and how it will respond to present and future climatic changes. Studies over the last few decades using a wide range of radio to microwave frequencies from a few $\mathrm{MHz}$ to a few $\mathrm{GHz}$ have shown that the radar-sounding method is a powerful tool for determining subsurface structures of large ice masses (e.g. Robin and others, 1969; Bogorodsky and others, 1985).

Within ice sheets, radio waves scatter off sudden changes of the complex dielectric permittivity of strata; thus, such scattering is often treated like that from internal reflections. Since the 1960s, the relative importance of two mechanisms for internal reflections has been determined. These mechanisms are changes of dielectric permittivity due to changes in density (hereafter denoted $P_{\mathrm{D}} ; P$ for permittivity and $\mathrm{D}$ for density) and changes of electrical conductivity due to changes in acidity (hereafter $C_{\mathrm{A}} ; C$ for conductivity and $\mathrm{A}$ for acidity).

\footnotetext{
* Present address: National Institute of Polar Research, Kaga, Itabashi-ku, Tokyo 173-8515, Japan.
}

$\dagger$ Present address: Department of Earth and Space Sciences, Box 351310, University of Washington, Seattle, WA 98195-1310, U.S.A.
However, a third mechanism, changes of dielectric permittivity due to changes in crystal-orientation fabrics (hereafter, $P_{\mathrm{COF}} ; P$ for permittivity and COF for crystal-orientation fabrics), has been debated since Harrison (1973) first speculated that $P_{\mathrm{COF}}$ might be one of the dominant reflection mechanisms. But this idea did not gain support for a long time. Recently, a few precise laboratory experiments found that ice single crystals have a dielectric anisotropy as large as about $1 \%$ over a wide frequency range from $\mathrm{MHz}$ to $\mathrm{GHz}$ (e.g. Fujita and others, 1993, 2000; Matsuoka and others, 1997). Based on the magnitude of the dielectric anisotropy, Fujita and Mae (1994) proposed that $P_{\mathrm{COF}}$ is a major cause of internal radio-wave reflections. Although our knowledge on the spatial fluctuation of the COF data along ice depths is very limited, several ice-core studies and borehole logging have proposed that sharp and also large changes of COF occur along depths on scales from several meters to millimeters. These studies are Azuma and others (2000), on a Dome Fdeep ice core, Lipenkov and Barkov (1998), on a Vostok deep ice core, Gow and Williamson (1976), on cloudy bands in a Byrd Station ice core, and Thwaites and others (1984), on the closure rate of a borehole at Cape Folger. Fujita and Mae (1994) and Fujita and others (2000) studied how three possible major causes $\left(P_{\mathrm{D}}, C_{\mathrm{A}}\right.$ and $\left.P_{\mathrm{COF}}\right)$ responded to changes of radar frequency and temperature, and proposed that multi-frequency radar sounding was a viable method to distinguish permittivity-based reflections $\left(P_{\mathrm{D}}\right.$ and $\left.P_{\mathrm{COF}}\right)$ and conductivity-based reflections $\left(C_{\mathrm{A}}\right)$. Fujita and others (1999) reported their experimental results of a 
(a)
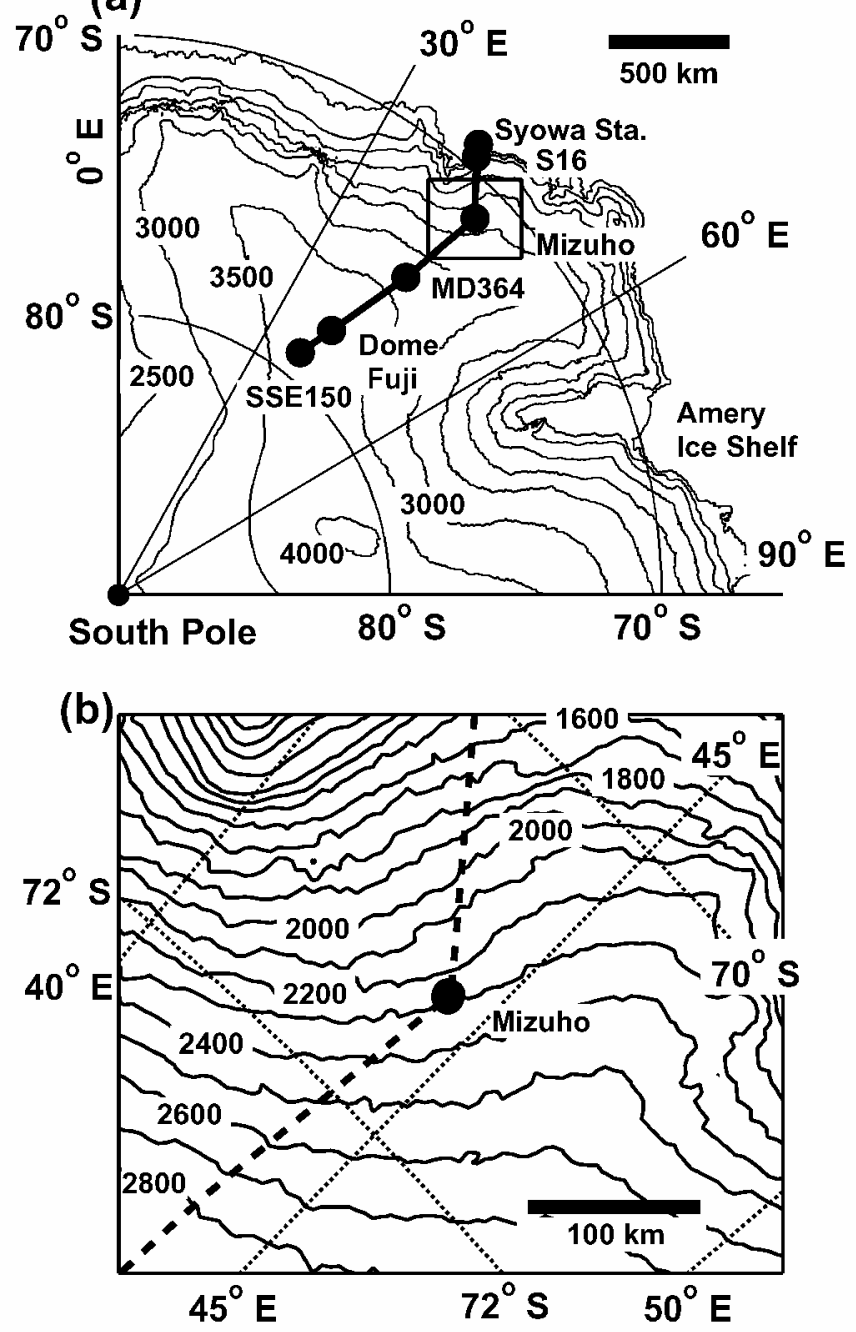

Fig. 1. Elevation map of East Antarctica and the location of Mizuho station $\left(70^{\circ} 42^{\prime} \mathrm{S}, 44^{\circ} 17^{\prime} \mathrm{E}\right.$; $2250 \mathrm{~m}$ a.s.l., ice thickness about $1950 \mathrm{~m}$ ). The ice flow is normal to the elevation contours. (a) Solid thick line indicates location of the major $1150 \mathrm{~km}$ long traverse route from the summit region of Dome Fuji, through Mizuho station, to Syowa station (Fujita and others, 1999, 2002). (b) Elevation contours near Mizuho station and site of the measurements (solid circle).

two-frequency radar sounding along a $1150 \mathrm{~km}$ long traverse in East Antarctica. They found that, at depths above about 700-900 m, the reflections are always caused by permittivity changes, and permittivity-based reflections occur widely in deeper ice, in particular at depths where high shearing is expected. Moreover, they found that conductivity-based reflections dominate near the dome summit. They then suggested that permittivity-based reflections in ice deeper than about $700-900 \mathrm{~m}$ are due to the $P_{\mathrm{COF}}$ mechanism. This was because, below this depth range, all air bubbles change into clathrate hydrate crystals, and air inclusions cannot explain any permittivity changes. For example, dielectric permittivity of $\mathrm{N}_{2}$ hydrate is about 2.8, smaller than that of ice (Gough, 1972). But its volume fraction in ice is extremely small, of the order of $3 \times 10^{-4}$ (e.g. Lipenkov, 2000), which cannot cause any permittivity changes significant for radar reflections. Fujita and others (1999) suggested that there could be many abrupt and significant changes of COF in the ice sheet, although this view is not widely accepted due to a lack of continuous COF analyses on ice cores. However, a few groups

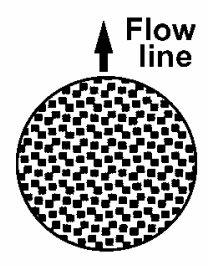

(a)

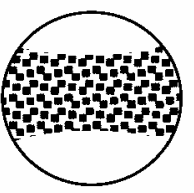

(b)

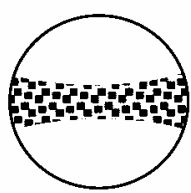

(c)

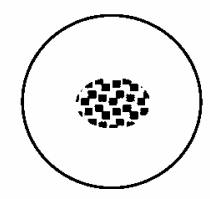

(d)
Fig. 2. Schmidt-net diagram sketches of typical $\mathrm{COF}$ development at Mizuho station. $(a-c)$ represent $\mathrm{COF}$ in the $700 \mathrm{~m}$ deep Mizuho station ice core; (d) is for deeper regions as deduced from the present work. The vertical axis is at the center. Development of vertical-girdle type with increasing depths was observed in the ice core as in $(a-c)$ (see Fujita and others, 1987). (d) is a typical single-pole COF expected in the simple shear zone deeper in the ice. Stacking of the vertical-girdle-type $\mathrm{COF}(c)$ and the single-pole COF (d) is needed to explain the strong radio scattering in the polarization plane along the transverse axis at 900-1500 m depths. This type of COF development was observed in the Vostok deep ice core (Lipenkov and others, 1989; Lipenkov and Barkov, 1998).

have recently developed automatic ice-fabric analyzers to better understand the detailed COF structure in polar ice sheets (e.g. Wang and Azuma, 1999). If future studies of COF structure support the COF scattering mechanism, then radioecho sounding could become a powerful tool for investigating $\mathrm{COF}$ in large regions of polar ice sheets.

Besides radio-wave reflections, COF controls birefringence effects within ice sheets. Since the crystals have a preferred orientation within ice sheets, the ice sheet itself should have a macroscopically anisotropic permittivity (e.g. Hargreaves, 1977). For example, the single-pole and the vertical-girdle-type $\mathrm{COF}$ are very common in ice sheets. In the single-pole COF , $c$ axes tend to cluster around the vertical. In the vertical-girdle-type COF, $c$ axes tend to rotate away from a horizontal axis toward a vertical plane normal to the axis (see, e.g., Paterson, 1994). Therefore, these COFs have uniaxial symmetry. Because Maxwell's equations allow radio-wave propagation only along the two principal axes of the dielectric permittivity, radar soundings can determine the principal axes of the $\mathrm{COF}$

If radio-wave reflections are due to $\mathrm{COF}$ and birefringence effects, one can obtain critical information about the COF and hence ice-sheet dynamics from the radar data. Mizuho station, Antarctica, (Fig. 1) has been used as a testing ground for radio birefringence and anisotropic echo methods, and ice-dynamics data have been obtained at this site (e.g. Yoshida and others, 1987; Maeno and others, 1995). Yoshida and others (1987) first carried out $179 \mathrm{MHz}$ radar sounding to detect the birefringence. They found that the echo strength of the internal scattering increased when the two parallel antenna azimuths were either parallel or perpendicular to the observed flowline. Because the flowline is parallel to the tensile principal strain, their data indicate that the COF might cause the birefringence. Direct COF measurements on the $700 \mathrm{~m}$ Mizuho station ice core (Fujita and others, 1987) showed that the $c$ axes of the grains tended to orient perpendicular to the flowline and that $c$ axes concentrated gradually on a vertical girdle with increasing depth (see the Schmidt-net diagrams in Fig. $2 \mathrm{a}-\mathrm{c}$ ). Using the data of ice dielectric anisotropy (Fujita and others, 1993), Fujita and Mae (1993) re-examined the radar measurements 
of Yoshida and others (1987) and calculated the dielectric permittivity tensor at 12 depths of the ice sheet at Mizuho station using the COF data. They showed that the ice sheet was uniaxially birefringent, with the symmetrical axis of rotation equal to the longitudinal axis of ice flow (or the flowline). They also argued that the dielectric permittivity tensor depended on depth. They then suggested that the birefringence caused the scattered power to increase when the two parallel antenna azimuths were parallel or perpendicular to the observed flowline. However, this did not fully explain the scattered power. Birefringence predicts that two principal orientations have a strong signal, but the observed signal was strong only in one of the two principal orientations (Fujita and Mae, 1993). The reason for this remains unclear, although there is some indication that the scattering coefficient is weaker in one principal direction.

In 1996/97, we did a more detailed polarization experiment at Mizuho station. Our purpose was to investigate relations between $\mathrm{COF}$ within ice and electromagnetic phenomena within ice such as birefringence and scattering. This radar survey was done by the 37 th Japanese Antarctic Research Expedition (JARE), which included a series of radar experiments along the $1150 \mathrm{~km}$ long traverse line from the Dome Fuji region to the coast (Fujita and others, 1998, 1999, 2002). For these measurements, we varied the following experimental parameters: (1) co-polarization and crosspolarization antenna arrangements; (2) all orientations of the antenna; (3) frequency (60 and $179 \mathrm{MHz}$ ); and (4) pulse lengths from 150 to $1000 \mathrm{~ns}$. These results suggested physical conditions of layered stratum in ice and revealed substantial information on how radio-wave scattering responds to these parameters. Moreover, the data suggested that the radio signals were controlled both by scattering at anisotropic boundaries and by birefringence. We propose that the scattering of radio waves at depths of about $900-1500 \mathrm{~m}$ is mostly from the stacking of single-pole COF layers with vertical-girdle COF layers. We also suggest that, at depths above about $750 \mathrm{~m}$, the observed anisotropic scattering is likely from the stacking of vertical-girdle-type fabrics with varying cluster strengths. Although our radar experiments are at a single site, the results suggest how similar remote measurements over wider regions can contribute to future understanding of the dynamical structure of the continental ice sheet. We emphasize that much more work should be done to explore the large potential of the polarimetric radar sounding for investigations of the internal structure of polar ice sheets.

\section{EXPERIMENT}

\section{Basic principle of polarimetric radar sounding}

We briefly describe the basic principles used in polarimetric radar soundings. By observing radar signals in two polarization planes and changing the polarization planes of transmitter and receiver with one another, one can obtain more information than from observations with a single fixed polarization plane. Most of the conventional radar soundings of polar ice sheets used a single fixed polarization plane. In our polarimetric radar soundings, we rotated the antennas and changed their polarization planes.

Generally, the radar equation describes basic relations between the transmitted signals and the propagation of radio waves in ice including geometrical spreading, attenuation, scattering and refraction, and also includes the specifications

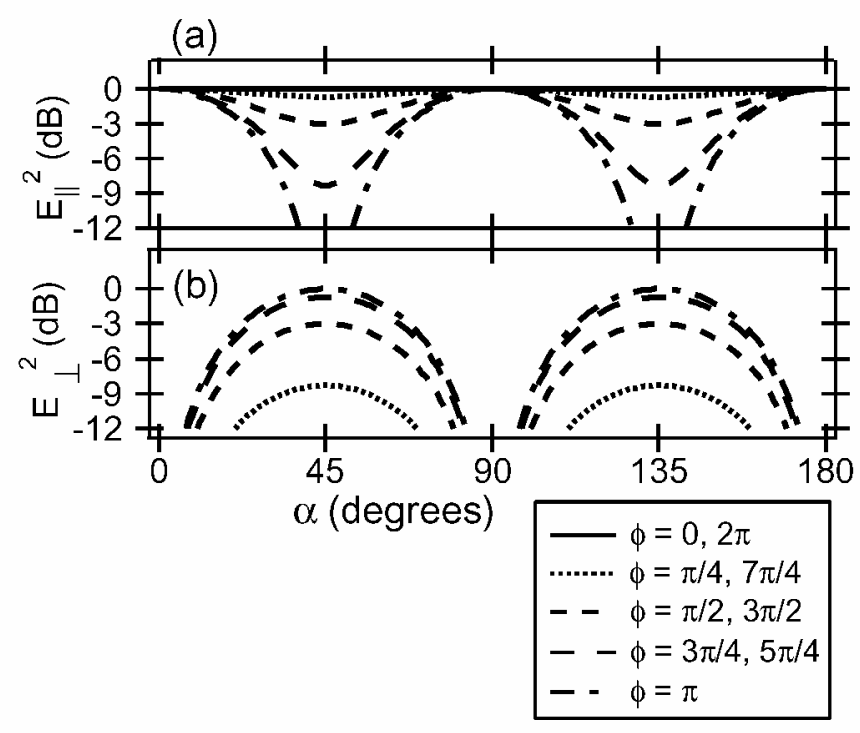

Fig. 3. Relative variation of the radio-wave power propagated through a uniaxially birefringent ice sheet based on the analysis in Hargreaves (1977). We assume that the symmetrical axis of birefringence is in the horizontal plane and the vertical-girdletype fabric of the $700 \mathrm{~m}$ Mizuho station ice core. (a) The relative variation of the received power is $E_{\|}^{2}$ and the antenna arrangement is $\mathrm{T}_{\mathrm{x}} \| \mathrm{R}_{\mathrm{x}}$ ( see text). $E_{\|}^{2}$ has the same meaning as in Hargreaves (1977); $E_{\|}^{2}$ means that the received power is the square of the electrical field. $E_{\|}^{2}$ is a function of antenna orientation $\alpha$, defined as the angle of $\mathrm{T}_{\mathrm{x}}$ from one of the two principal axes, and $\phi$ is the phase difference between the ordinary and the extraordinary wave. $\phi$ is a function of both anisotropy in the dielectric permittivity tensor in ice and radio frequency. The two principal axes are assumed to be at $0^{\circ}$ and $90^{\circ}$. (b) The relative variation of the received power for the $\mathrm{T}_{\mathrm{x}} \perp \mathrm{R}_{\mathrm{x}}$ antenna arrangement is ${E_{\perp}}^{2}$. Antenna orientation $\alpha$ is the angle of $\mathrm{T}_{\mathrm{x}}$ from one of the two principal axes. Signals drop when $\alpha$ is along a principal axis.

of the radar systems. The radar equation used here is described in Fujita and others $(1999,2002)$ for layered scattering boundaries. However, that equation does not include effects from (1) birefringence and (2) anisotropic scattering boundaries. Therefore, we clarify here how these two phenomena influence the radar power.

\section{Effects from birefringence}

Birefringence in ice is often revealed by the transmitting of various colors through ice thin sections between crossed polaroids (e.g. Langway, 1958). In the radio experiments, dipole antennas or Yagi antennas act as imperfect polarizers. These types of antennas transmit and receive radio-wave components mostly in the orientation of the antenna, but side lobes of the antenna radiation pattern produce weak components in various orientations. Therefore, the polarizers are generally less perfect than those for light waves. If the ice sheet has principal axes of birefringence in the horizontal plane, then incident, linearly polarized waves are resolved into two components: the ordinary wave and the extraordinary wave. These two components propagate and scatter separately in ice. Some of the scattered components return to the ice-sheet surface. When these two components appear from the ice sheet to the air, they superimpose into an elliptically polarized wave. A receiver antenna acts as the second polarizer; it detects mostly the electrical field components 


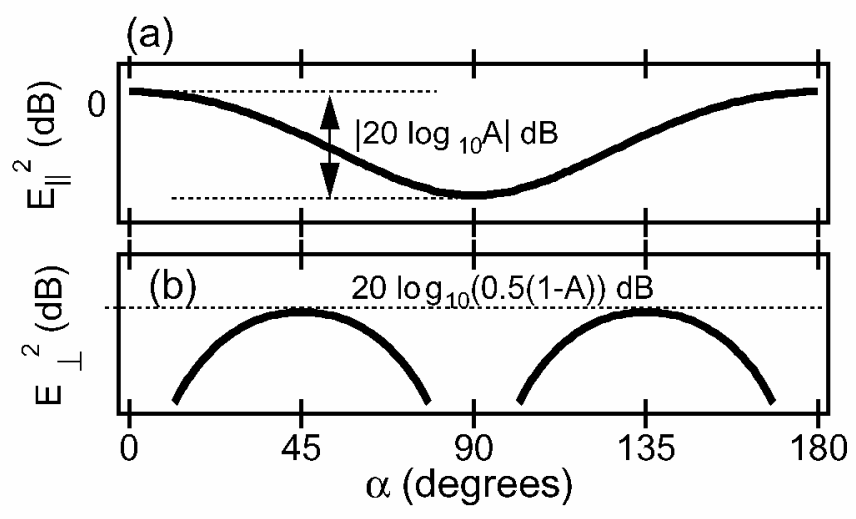

Fig. 4. Relative variation of the received power of radio waves scattered from an isotropic ice sheet containing anisotropic scattering boundaries based on the analysis in Hargreaves (1977). We assume that the principal axis of the anisotropic reflection coefficient is at orientations of $0^{\circ}$ and $90^{\circ}$. We also assume that the amplitude reflection coefficient at $90^{\circ}$ is less than that at $0^{\circ}$ by a factor of $A(A<1)$. (a) Antenna arrangement is $\mathrm{T}_{\mathrm{x}} \| \mathrm{R}_{\mathrm{x}}$. The relative variation of the received power is $E_{\|}^{2}$, which depends on antenna orientation $\alpha$, defined as the angle of $\mathrm{T}_{\mathrm{x}}$ from one of the two principal axes. The variation amplitude of $E_{\|}^{2}$ is $\left|20 \log _{10}(A)\right| \mathrm{d} B$. For example, an $A$ of 0.5 and 0.1 give amplitudes of 6 and $20 \mathrm{~dB}$, respectively. Maxima and minima appear every $90^{\circ}$. (b) Antenna arrangement is $\mathrm{T}_{\mathrm{x}} \perp \mathrm{R}_{\mathrm{x}}$. The relative variation of the received power is $E_{\perp}{ }^{2}$, which depends on $\alpha$. Antenna orientation $\alpha$ is the angle of $\mathrm{T}_{\mathrm{x}}$ from one of the principal axes. Signals drop when $\alpha$ is along a principal axis. The signal strength at the maximum is less than the maximum of $E_{\|}^{2}$ by $20 \log _{10}[0.5(1-A)] \mathrm{d} B$. For example, when $A$ has values 0.5 and 0.1, the decreases are 12 and $7 \mathrm{~dB}$.

parallel to the antenna. Depending on the phase difference $\phi$ between the ordinary waves and the extraordinary waves, the waves superimpose either constructively or destructively.

Figure 3 has examples of birefringence for co-polarized and cross-polarized antenna arrangements. For the co-polarized measurement, i.e. when the transmitting antenna $T_{x}$ is kept parallel to receiving antenna $R_{\mathrm{x}}$ (hereafter denoted as $\left.\mathrm{T}_{\mathrm{x}} \| \mathrm{R}_{\mathrm{x}}\right)$ and rotated together, a larger power is received when the angle between one of the principal axes and polarization plane is smaller. Thus, maxima and minima of the signal appear alternatively at every integral of $45^{\circ}$. The ratio of the power between the maxima and the minima depends on $\phi$. The average ratio is $3 \mathrm{~dB}$ (or 2 on the linear scale). This is the averaged number over both all orientations of the antennas and all phase differences, $\phi$, between the two components. When $\phi$ is close to $\pi$, the ratio can be larger. Therefore, when the observed ratio of the maximum to minimum power is very large, $\phi$ should be close to $\pi$. However, if the received power is averaged over some depth over a cycle of $\phi$, the birefringence causes the received power to vary by about $3 \mathrm{~dB}$. Also, the signals measured by pulse-modulated radars are essentially interference patterns from many scattering events within a pulse (see, e.g., Moore, 1988; Jacobel and Hodge, 1995). Therefore, the phase of the returned waves should fluctuate significantly.

In cross-polarized measurements, i.e. when the transmitting antenna $T_{x}$ is kept perpendicular to the receiving antenna $R_{x}$ (hereafter, $T_{x} \perp R_{x}$ ) as both rotate together, the received signal is smallest when the antennas are oriented along the principal axes of the birefringence (Fig.
$3 \mathrm{~b})$. This is similar to the extinction of light through an ice section between crossed polaroids. Depending on the orientation of the principal axes of birefringence, the polarized electrical field from $T_{\mathrm{x}}$ cannot be transmitted to the orthogonal polarization plane. Therefore, the intensity at $\mathrm{R}_{\mathrm{x}}$ is low.

\section{Effects from anisotropic scattering boundaries}

If the scattering boundaries within the ice sheet have anisotropic reflectivity with uniaxial symmetry, the received power responds differently to the polarimetric radar sounding (Hargreaves, 1977). For anisotropic scattering in $T_{x} \| R_{x}$ measurements, power maxima and minima appear every $90^{\circ}$ (Fig. 4 a). The ratio between the maximum and minimum power depends on the ratio between the maxima and the minima of the anisotropic reflectivity. For $T_{x} \perp R_{x}$ measurements, the received power is smallest when the antennas are oriented along the principal axes of the anisotropic scattering boundaries (Fig. 4b). Because of the symmetry of the scattering coefficient about the principal axis, the scattered waves along one principal axis do not contribute to the electrical field in the orthogonal plane. Thus, the maximum received signal in $T_{x} \perp R_{x}$ measurements is always smaller than that in $T_{x} \| R_{x}$ measurements. As indicated in Figure $4 b$, the ratio between $T_{\mathrm{x}} \perp \mathrm{R}_{\mathrm{x}}$ and $\mathrm{T}_{\mathrm{x}} \| \mathrm{R}_{\mathrm{x}}$ maxima depends on anisotropy in the scattering boundaries, and this ratio will be less distinct in practice because the polarizers are imperfect.

\section{Criteria to distinguish two different effects}

In real ice sheets, both birefringence effects and anisotropic scattering boundaries will occur, but the features from the dominant effect will have the clearest influence on the signal. We assume that when both effects occur in the same region of ice, the principal axes of the birefringence equal the principal axes of the anisotropic scattering boundaries. This assumption is justified because both effects are based on the symmetric structure of the COF, and furthermore, this assumption simplifies the problem.

Hargreaves (1977) originally proposed the following criteria to determine which mechanism is dominating the scattering signal. One first determines the major angles between the maxima and minima in the $T_{x} \| R_{x}$ measurement. An angle of $90^{\circ}$ indicates anisotropic scattering boundaries, whereas an angle of $45^{\circ}$ indicates birefringence. If both effects occur, these two variations would be superimposed with common principal axes. In case birefringence dominates, the ratio between the maxima and minima signal would provide $\phi$ as described for Figure 3. When anisotropic scattering boundaries dominate, the ratio between the maxima and minima would provide the magnitude of the anisotropy in scattering boundaries as shown in Figure 4. Whichever effect dominates, one can easily find the principal axes by referring to the signal variations in Figures 3 and 4. By measuring $\mathrm{T}_{\mathrm{x}} \perp \mathrm{R}_{\mathrm{x}}$, one can check to see if the observed phenomenon is from either or both of the two effects. For example, an important feature of the theory of birefringence is that a maximum of one $\left(T_{x} \| R_{x}\right.$ or $\left.T_{x} \perp R_{x}\right)$ component coincides with the minima of the other (that is, $T_{x} \perp R_{x}$ or $T_{x} \| R_{x}$, respectively) as shown in Figure $3 a$ and b. Also, an important feature of the theory of anisotropic scattering is that the minimum of the $\mathrm{T}_{\mathrm{x}} \perp \mathrm{R}_{\mathrm{x}}$ component coincides with either maxima or minima of the $T_{x} \| R_{x}$ component (Fig. 4a and b). These features appear in our data. 
Table 1. Specifications of the two radar systems used in this experiment

\begin{tabular}{|c|c|c|c|}
\hline \multicolumn{2}{|l|}{ Carrier frequency } & $60 \mathrm{MHz}$ & $179 \mathrm{MHz}$ \\
\hline \multirow[t]{2}{*}{ Transmitter } & Peak power & $1 \mathrm{~kW}$ & $1 \mathrm{~kW}$ \\
\hline & Pulse width & $250 \mathrm{~ns} / 1000 \mathrm{~ns}$ & $150 \mathrm{~ns} / 350 \mathrm{~ns} / 1050 \mathrm{~ns}$ \\
\hline Receiver & Sensitivity & $-115 \mathrm{dBm}^{\mathrm{a}}$ & $-115 \mathrm{dBm}$ \\
\hline \multirow[t]{3}{*}{ Antenna } & Type & 3 element Yagi & 3 element Yagi \\
\hline & Gain & $7.2 \mathrm{dBi}^{\mathrm{b}}$ & $8.15 \mathrm{dBi}$ \\
\hline & Beam width & $70^{\circ}$ & $70^{\circ}$ \\
\hline \multicolumn{2}{|c|}{ Vertical resolution in ice } & $21 \mathrm{~m} / 85 \mathrm{~m}$ & $13 \mathrm{~m} / 30 \mathrm{~m} / 89 \mathrm{~m}$ \\
\hline \multicolumn{2}{|l|}{ Waveleng th in ice } & $2.8 \mathrm{~m}$ & $0.94 \mathrm{~m}$ \\
\hline
\end{tabular}

${ }^{a} \mathrm{dBm}$ is a unit for expression of power level in decibels with reference to a power of $1 \mathrm{~mW}$. Receiver sensitivity is for after averaging processing to reduce the noise level.

${ }^{\mathrm{b}} \mathrm{dBi}$ is a unit for expression of antenna gain in decibels with reference to a power of an ideal isotropic antenna.

\section{Radar systems and the method of polarimetric radar sounding}

We used a 179 and a $60 \mathrm{MHz}$ pulse-modulated radar; the specifications for the transmitters, receivers and recorders for each radar system are given in Table 1 . To investigate the effects of radar pulse lengths (i.e. vertical resolution) for the $179 \mathrm{MHz}$ radar, we used 150, 350 and $1000 \mathrm{~ns}$. For the $60 \mathrm{MHz}$ radar, we used 250 and $1000 \mathrm{~ns}$. Each radar system was mounted on its own snow vehicle. The radar system used here was used and calibrated along the $1150 \mathrm{~km}$ traverse that passed through Mizuho; in this paper, we describe only the Mizuho results. The transmitting antenna $T_{\mathrm{x}}$ and the receiving antenna $R_{x}$ were on opposite sides of the vehicle and were either parallel or perpendicular to each other (Fig. 5). All data were digitally recorded. To calibrate the received power, we regularly calibrated a relation between the power from the antenna and the output in the recording system during the experiments, which were done from 1996 to 1997 (e.g. Fujita and others, 1999, 2002).

For $T_{\mathrm{x}} \| \mathrm{R}_{\mathrm{x}}$ measurements, we made time series of the radar return power $P_{\mathrm{R}}$ in 16 antenna azimuths by changing the direction of the vehicle. For the starting orientation, $T_{x}$, $R_{x}$ and the vehicle were oriented to true north. They were

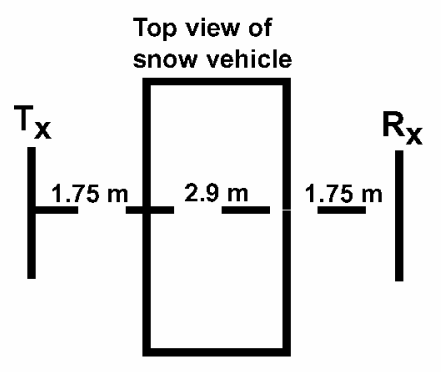

(a) $T_{x} \| R_{x}$

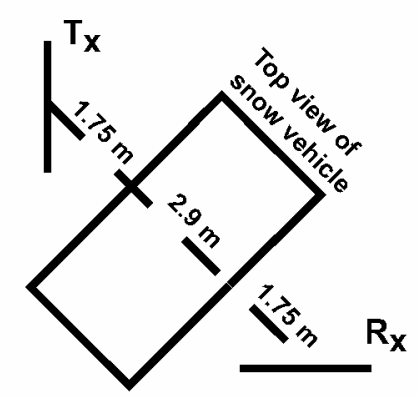

(b) $T_{x} \perp R_{x}$
Fig. 5. Top view of the antenna arrangements. For both arrangements, the transmitting and receiving antennas are at opposite sides of the snow vehicle (rectangle in the figure). $\mathrm{T}_{\mathrm{x}}$ and $\mathrm{R}_{\mathrm{x}}$ represent transmitting and receiving antennas, respectively. (a) Antenna arrangement for $\mathrm{T}_{\mathrm{x}} \| \mathrm{R}_{\mathrm{x}}$ measurements. (b) Antenna arrangement for $\mathrm{T}_{\mathrm{x}} \perp \mathrm{R}_{\mathrm{x}}$ measurements. The centers of $\mathrm{T}_{\mathrm{x}}$ and $\mathrm{R}_{\mathrm{x}}$ were separated by $6.4 \mathrm{~m}$, and they were $3.2 \mathrm{~m}$ above the icesheet surface. Antenna lengths were 0.75 and $2.34 \mathrm{~m}$ for 179 and $60 \mathrm{MHz}$, respectively.

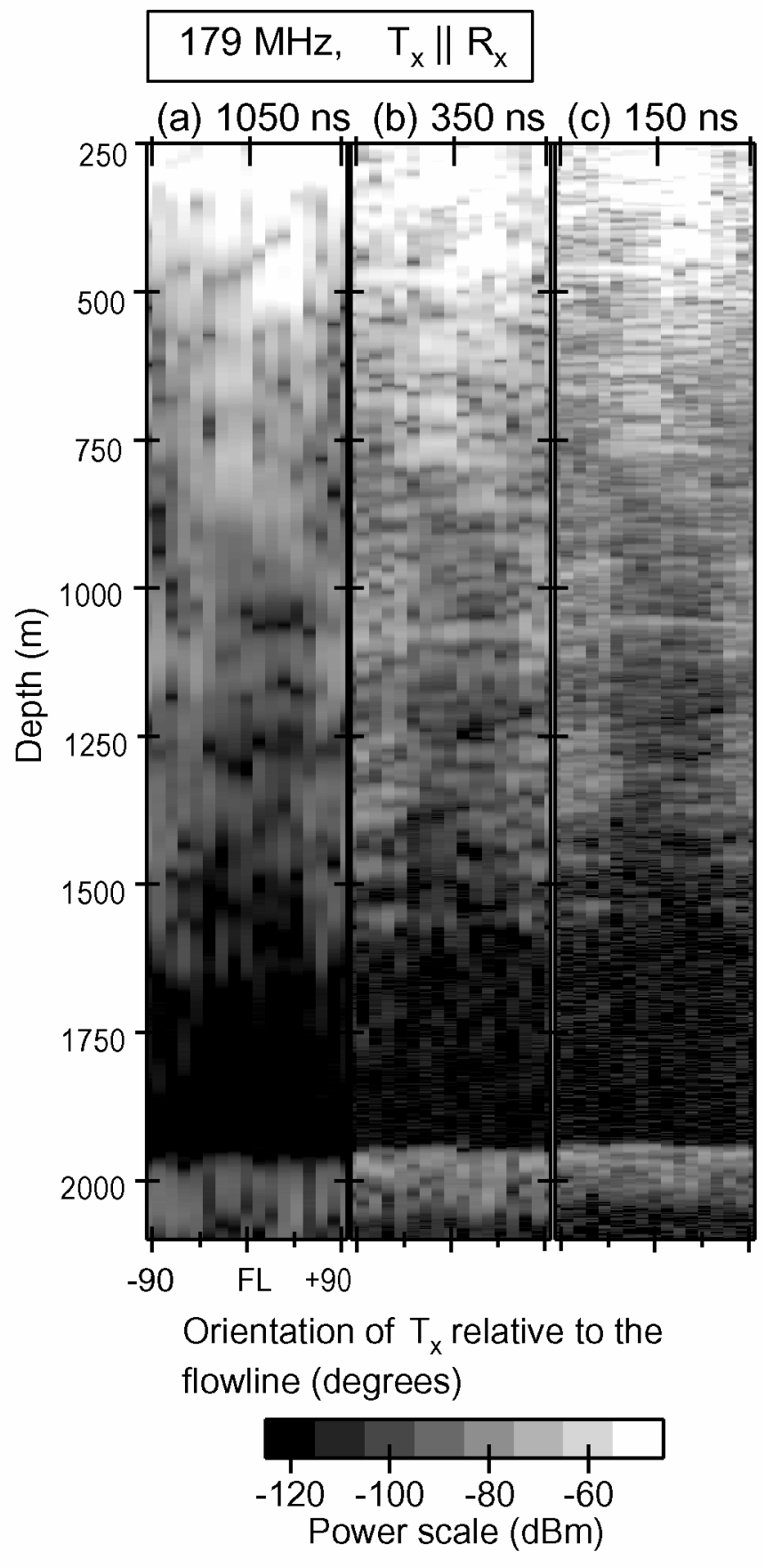

Fig. 6. Radar scattering from ice for the $\mathrm{T}_{\mathrm{x}} \| \mathrm{R}_{\mathrm{x}}$ arrangement at $179 \mathrm{MHz}$. Abscissa is the $\mathrm{T}_{\mathrm{x}}$ orientation relative to the flowline. The flowline is from $117^{\circ}$ to $279^{\circ}$ geographically and its orientation is denoted "FL". Ordinate is the depth of ice converted from time data. Received power $P_{\mathrm{R}}(\mathrm{dBm})$ is expressed by the gray scale shown at the bottom. Strong signals are white, and weak signals are dark. Images $(a-c)$ are from radar pulse lengths of 1050, 350 and 150 ns, respectively. Received power $P_{\mathrm{R}}$ decreases with increasing depth due to geometrical spreading and attenuation of the radio wave. Strong scattering at about $1950 \mathrm{~m}$ is from the ice-bedrock boundary. Between 1500 and $1950 \mathrm{~m}$ is an echo-free zone due to weak scattering and abrupt drop of received power level at $1500 \mathrm{~m}$ (see Fujita and others, 1999, for details). For image (a), $P_{\mathrm{R}}(\mathrm{dBm})$ was reduced by $10 \mathrm{~dB}$ from the originally observed values so that the same gray scale could be used for all three images.

then rotated in clockwise increments of $11.25^{\circ}(\pi / 16 \mathrm{rad})$ until $180^{\circ}$ was reached. Due to symmetry of the radio-wave propagation and scattering around the vertical, orientations $0-180^{\circ}$ are sufficient to describe all angles. We verified 
(a)

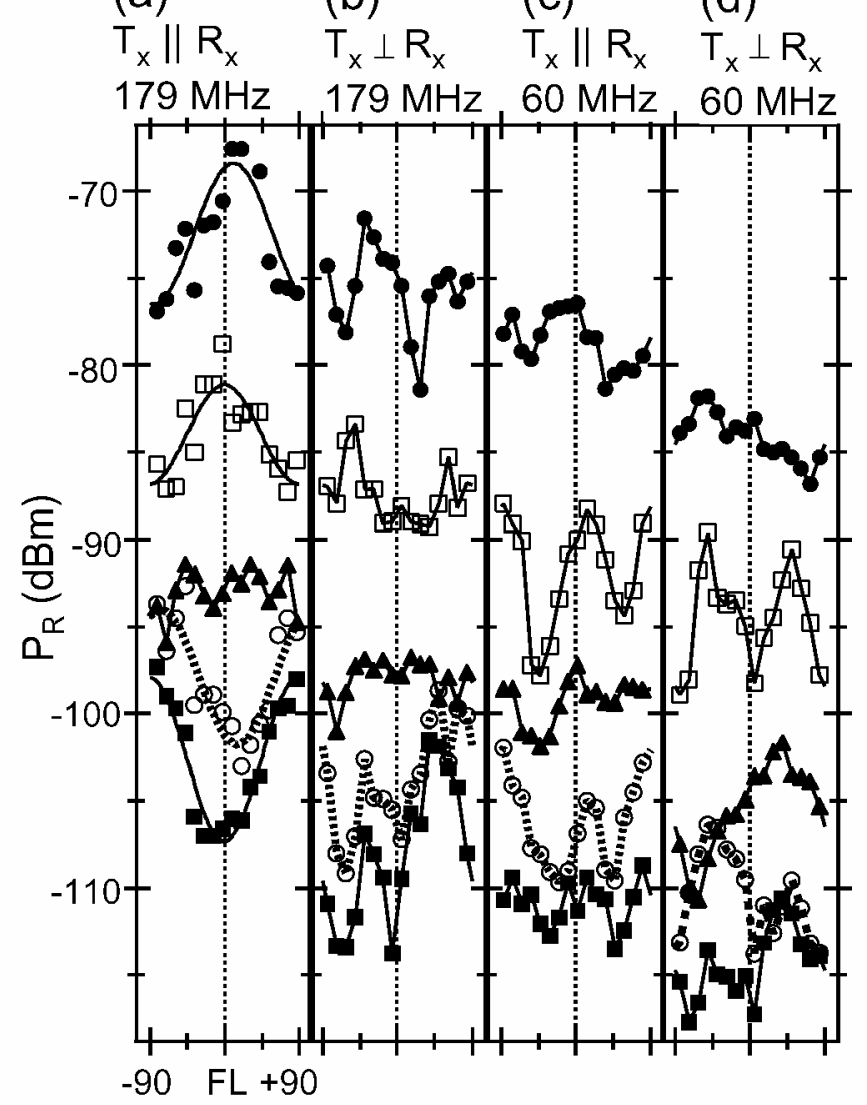

Orientation of $T_{x}$ relative to the flowline (degrees)

$$
\begin{array}{|l|}
\hline \text { Depth range } \\
-250-500 \mathrm{~m} \\
\square-500-750 \\
-750-1000 \\
-9-1000-1250 \\
-1250-1500
\end{array}
$$

Fig. 7. Variation of $P_{\mathrm{R}}$ as a function of antenna orientation for four experimental conditions. $P_{\mathrm{R}}$ was averaged over each $250 \mathrm{~m}$ from the raw results shown in Figures 6,8 and 9. Because this averaging distance is much larger than the pulse length in ice ( Table 1), the averaged values show signal variations of $P_{\mathrm{R}}$ without interference effects. From left to right, the experimental conditions are (a) $\mathrm{T}_{\mathrm{x}} \| \mathrm{R}_{\mathrm{x}}, 179 M H z$ with 350 ns pulse; ( $b$ ) $\mathrm{T}_{\mathrm{x}} \perp \mathrm{R}_{\mathrm{x}}, 179$ MHz with 350 ns pulse; (c) $\mathrm{T}_{\mathrm{x}} \| \mathrm{R}_{\mathrm{x}}, 60 M H z$ with 250 ns pulse; (d) $\mathrm{T}_{\mathrm{x}} \perp \mathrm{R}_{\mathrm{x}}$, $60 \mathrm{MHz}$ with 250 ns pulse. In (a), we fitted the data to sinusoidal curves, except the 750-1000 m data. The error caused by the interference effect is about $\pm 1 d B$.

this by a number of cross-checks during our experiments. We checked that the results near $0^{\circ}$ and near $180^{\circ}$ were the same at the start of the route, and did the same cross-check at a number of sites along the $1150 \mathrm{~km}$ long traverse from Dome $\mathrm{F}$ to the coast. Furthermore, at Dome F, the results from $0^{\circ}$ to $180^{\circ}$ agreed very well with the results from $180^{\circ}$ to $360^{\circ}$. In the measurements, orientations were determined using a magnetic compass with errors within a few degrees for each orientation. For $\mathrm{T}_{\mathrm{x}} \perp \mathrm{R}_{\mathrm{x}}$ measurements, the antennas were rotated in the same manner as in the $T_{x} \| R_{x}$ measurements.

The detection limit of the present measurements was less than $-115 \mathrm{dBm}$ (Table 1). All of the data used here are from

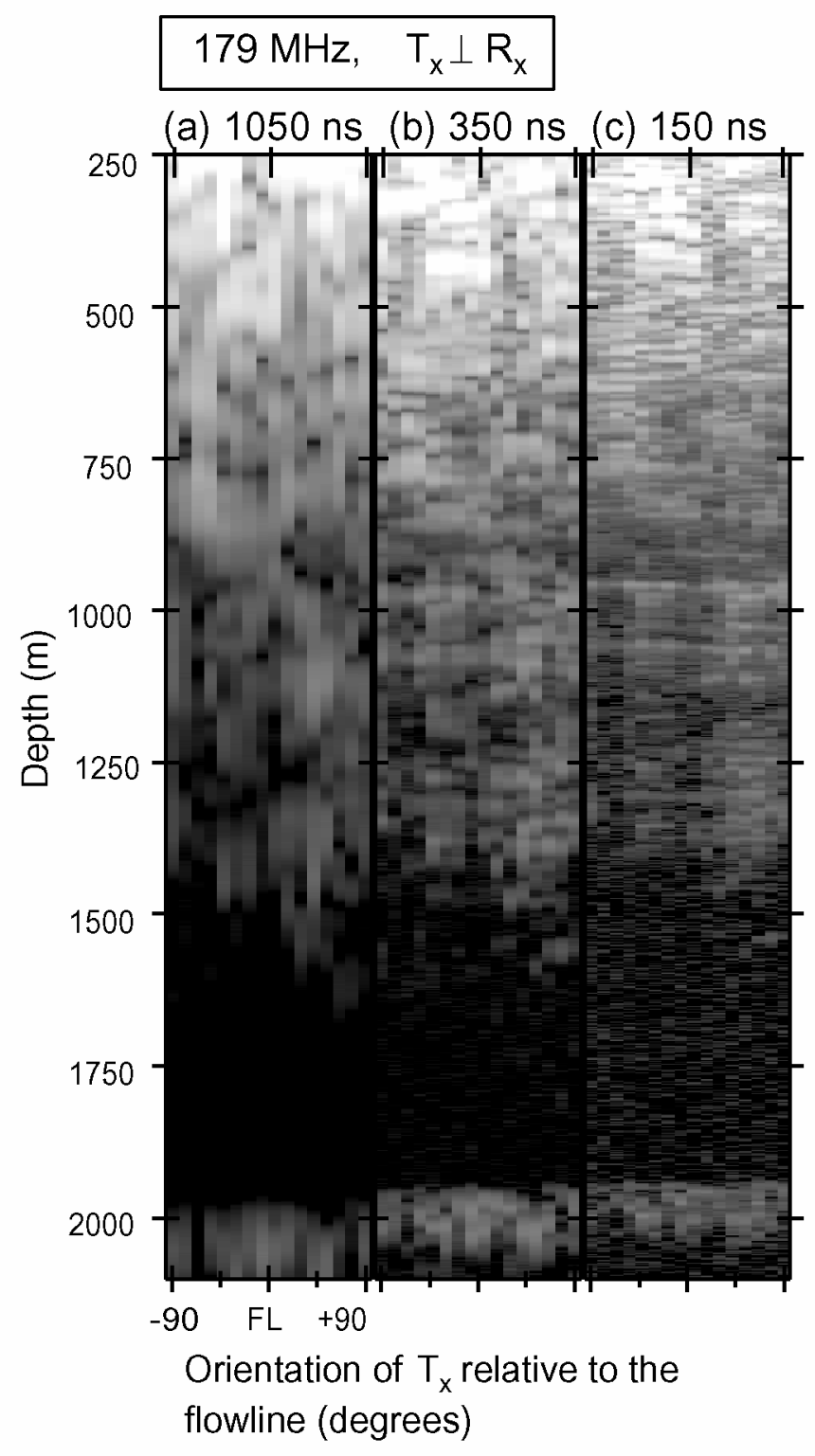

Fig. 8. Radar scattering from ice for the $\mathrm{T}_{\mathrm{x}} \perp \mathrm{R}_{\mathrm{x}}$ arrangement at $179 \mathrm{MHz}$. The abscissa is the orientation of $\mathrm{T}_{\mathrm{x}}$ relative to the flowline. $\mathrm{R}_{\mathrm{x}}$ is always oriented perpendicular to $\mathrm{T}_{\mathrm{x}}$ as shown in Figure 5b. In all other respects, including the gray scale, the features are the same as in Figure 6.

-65 to about $-115 \mathrm{dBm}$ (e.g. Figs 6 and 7), which is above the detection limit. Also, we calibrated the system frequently and the total error in the received power is $<1 \mathrm{~dB}$, so we consider any variation in the time series that exceeds $1 \mathrm{~dB}$. But because the signals measured by pulse-modulated radars are essentially interference patterns from many scattering events within a pulse (e.g. Moore, 1988; Jacobel and Hodge, 1995), it is meaningless to discuss each fluctuation of radar signals within a pulse unless discussions are linked with all of the following information on reflectors: (i) exact locations, (ii) distances, (iii) thickness, (iv) types of reflectors (that is, $P_{\mathrm{D}}, C_{\mathrm{A}}$ or $\left.P_{\mathrm{COF}}\right),(\mathrm{v})$ orientation of polarization plane, (vi) pulse length, and (vii) radar frequencies. In contrast, one should consider these factors when analyzing the average tendency. We focus on the average tendency in this paper and we do not discuss any single fluctuation.

\section{Glaciological conditions of the observation site}

The ice sheet near Mizuho station is in the Shirase Glacier 
drainage basin, where ice flow converges toward the outlet glacier (Fig. 1b). The flow vector of the ice sheet is $22.2 \mathrm{~m} \mathrm{a}^{-1}$ in the direction of $297^{\circ}$ (Motoyama and others, 1995). The principal strain was derived as tensile in the longitudinal direction and compression in the transverse direction (Naruse and Shimizu, 1978). At Mizuho station, Yoshida and others (1987) did experiments at a point $0.2 \mathrm{~km}$ west of the main buildings of the station. Our new experiment was done at a point $0.2 \mathrm{~km}$ east of the main buildings of the station to avoid possible interference between our radar experiment and facilities of the station. Therefore, the distance between two sites is $0.4 \mathrm{~km}$. At the station, a $700 \mathrm{~m}$ long core was drilled in 1983 and 1985 (Higashi and others, 1988). The COFs of the $700 \mathrm{~m}$ long core are vertical-girdle type due to tensile strain, and this type develops with increasing depth (Fujita and others, 1987).

\section{RESULTS}

\section{Response of received power $P_{\mathrm{R}}$ to polarimetric radar sounding at $179 \mathrm{MHz}$}

The $\mathrm{T}_{\mathrm{x}} \| \mathrm{R}_{\mathrm{x}}$ measurements at $179 \mathrm{MHz}$ show that the dependence of $P_{\mathrm{R}}$ on antenna orientation is different for depths above and below $\sim 750 \mathrm{~m}$ (Fig. 6). At depths above about $750 \mathrm{~m}, P_{\mathrm{R}}$ is strongest for antenna orientations near the flowline and weakest for antenna orientations perpendicular to the flowline. Here, the orientation is expressed as an angle relative to the flowline. Hereafter, we denote an orientation perpendicular to the ice flow as "transverse". Because the angle between the maxima and minima is $90^{\circ}$, anisotropic scattering boundaries have strong effects. This feature was found to be independent of pulse length and thus is unlikely to be caused by interference within a pulse. Although the pulse-modulated radar signals are essentially interference patterns from multiple scatterings within a pulse, we confirmed that changes of vertical resolution (i.e. pulse lengths) did not affect the general trends in $P_{\mathrm{R}}$. On the other hand, small fluctuations of the order of several $\mathrm{dB}$ over depth ranges as narrow as the pulse lengths (see Table 1) indicate interference effects. But, the average trends over significant depths are clear. To better illustrate the variation trends with depth, the raw $P_{\mathrm{R}}$ data were averaged over each $250 \mathrm{~m}$ (Fig. 7a). At depths of $250-500 \mathrm{~m}$, the variation amplitude is about $10 \mathrm{~dB}$. At depths of $500-750 \mathrm{~m}$, the variation amplitude is about $8 \mathrm{~dB}$. At depths of $750-1000 \mathrm{~m}$, the variation is smallest.

An interesting feature is that the orientations of maxima and minima are opposite at depths below about $900 \mathrm{~m}$ as compared with regions closer to the surface (Figs 6 and 7a). That is, below about $900 \mathrm{~m}$, the maxima appear along the transverse line, whereas the minima appear along the flowline. This feature appears in the three images of Figure 6 and in Figure $7 \mathrm{a}$. The variation amplitude is about $10 \mathrm{~dB}$ at depths below about $900 \mathrm{~m}$. Although the maxima and the minima switch between shallow and deep regions, the principal axes have the same orientations; in both cases, they are along the flowline and the transverse line.

The $\mathrm{T}_{\mathrm{x}} \perp \mathrm{R}_{\mathrm{x}}$ measurements at $179 \mathrm{MHz}$ showed features in agreement with theory. Figures $7 \mathrm{~b}$ and 8 show clear variations of $P_{\mathrm{R}}$ with antenna orientations. At most depths where the signal is above the detection limit, the $P_{\mathrm{R}}$ signals are strong at about $45^{\circ}$ from the principal axes on both sides, as theory predicts in Figure 4. Also, minima appear mostly at the two principal axes, which also agrees with Figure 4.
As in the $T_{x} \| R_{x}$ measurements, little variation occurs between about 750 and $1000 \mathrm{~m}$. As in the previous figure, these features are common to the three pulse lengths and thus are unlikely to be interference effects.

All of the features in the $T_{x} \| R_{x}$ measurements are consistent with earlier $\mathrm{T}_{\mathrm{x}} \| \mathrm{R}_{\mathrm{x}}$ observations at Mizuho. For example, Yoshida and others (1987, fig. 5) and Fujita and Mae (1993, fig. 2) pointed out that both the $90^{\circ}$ angle between the maxima and minima, and the maxima and minima switch between shallow and deep regions. This agreement shows the consistency and reliability of the measurements.

\section{Response of received power $P_{\mathrm{R}}$ to polarimetric radar sounding at $60 \mathrm{MHz}$}

The orientation dependence of $P_{\mathrm{R}}$ is weaker at the lower frequency of $60 \mathrm{MHz}$. For example, the gray-scale images for $\mathrm{T}_{\mathrm{x}} \| \mathrm{R}_{\mathrm{x}}$ in Figure $9 \mathrm{a}$ and $\mathrm{b}$ do not show a very clear trend of $P_{\mathrm{R}}$ with orientation. However, peaks at the flowline and the transverse line clearly appear when the signals are averaged over each $250 \mathrm{~m}$ (Fig. 7c). The angles between maxima and minima are near $45^{\circ}$ at most depths. According to the theory, this is a typical feature of birefringence. As with the $179 \mathrm{MHz}$ data, the variation is much weaker at $750-1000 \mathrm{~m}$.

An interesting feature is that, at depths below $750 \mathrm{~m}$, the $P_{\mathrm{R}}$ signals for the $60 \mathrm{MHz} \mathrm{T}_{\mathrm{x}} \| \mathrm{R}_{\mathrm{x}}$ measurement have features in common with those of the $179 \mathrm{MHz}$ measurements (cf. Fig. $7 \mathrm{a}$ and c). Although the $60 \mathrm{MHz}$ data in Figure 7c have additional maxima, the large maxima are common to the $179 \mathrm{MHz}$ data in Figure 7a. Such comparisons between frequencies have important implications for the operation of a common scattering mechanism in ice, as discussed in the next section.

The gray-scale images for $\mathrm{T}_{\mathrm{x}} \perp \mathrm{R}_{\mathrm{x}}$ in Figure 9 show clear variations of $P_{\mathrm{R}}$ with antenna orientations (Fig. 9c and d). At most depths where the signal is above the detection limit, $P_{\mathrm{R}}$ signals tend to be strong at two orientations, about $45^{\circ}$ away from the flowline and transverse line, whereas minima occur near the flowline and near the transverse line. These features are common to both pulse lengths, indicating that they are not interference artifacts. Furthermore, except at 250-500 $\mathrm{m}$ and $750-1000 \mathrm{~m}$, the averaged data show clear variations (Fig. 7d).

In addition to the $45^{\circ}$ angles between maxima and minima in the $T_{x} \| R_{x}$ measurement, the data agree with birefringence theory (Fig. 3) in another way. Theory predicts that a maximum of one $\left(T_{x} \| R_{x}\right.$ or $\left.T_{x} \perp R_{x}\right)$ component coincides with the minima of the other (that is, $T_{x} \perp R_{x}$ or $T_{x} \| R_{x}$, respectively). Figure $7 \mathrm{c}$ and $\mathrm{d}$ agree with this prediction at most depths where the signal showed clear variations.

\section{DISGUSSION AND INTERPRETATION}

Many observed features agreed well with theories of either (1) birefringence, (2) anisotropic scattering boundaries, or both. We first discuss how birefringence and anisotropic scattering boundaries occur in the ice sheet. In particular, we focus on the causes of radio-wave scattering in the ice sheet and its dependence on frequency. Second, we suggest that $\mathrm{COF}$ varies with depth at Mizuho. Third, we discuss abrupt changes of COFs in the Antarctic ice sheet. Finally, we describe how the method can be extended to measurements over wide areas. 


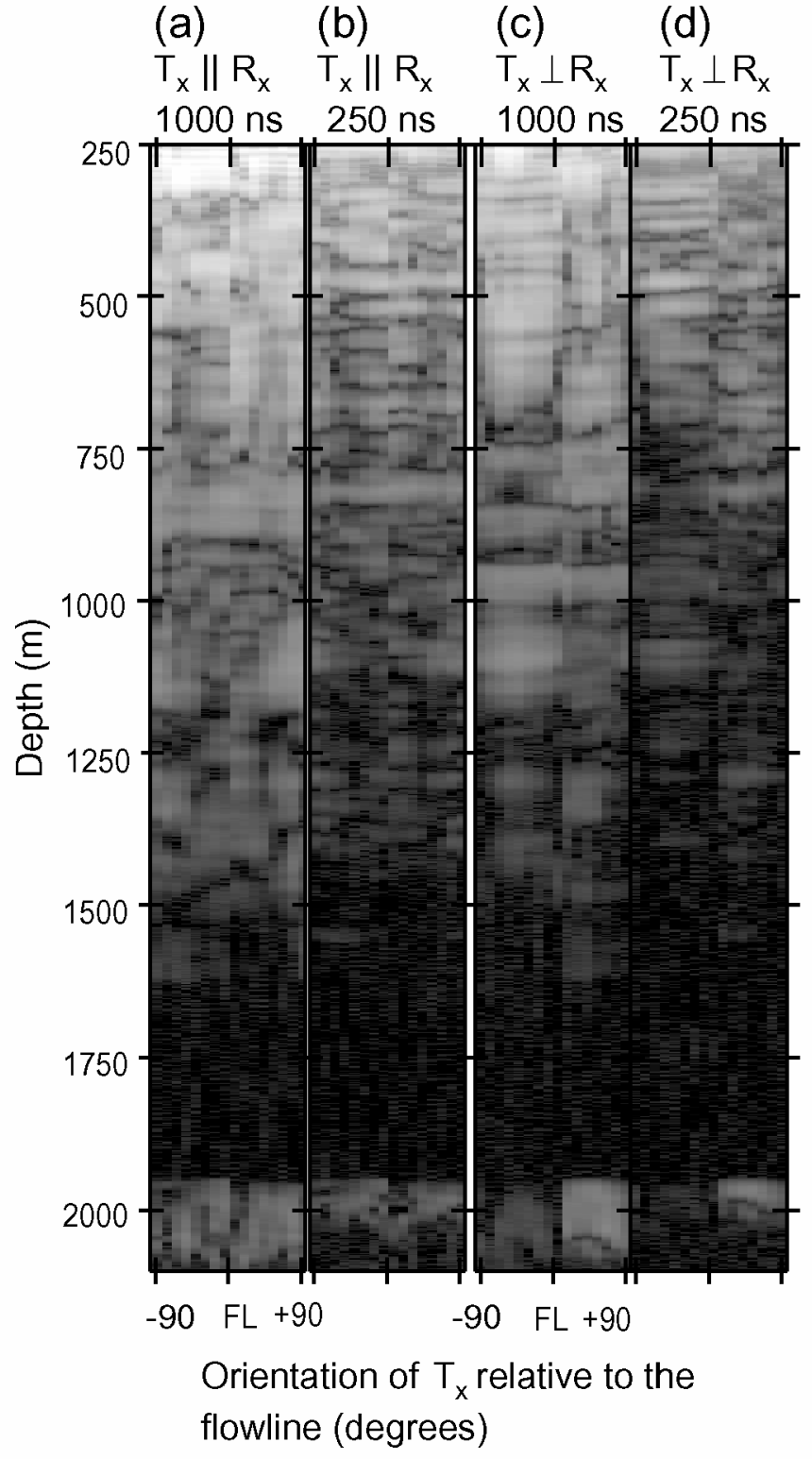

Fig. 9. $\mathrm{T}_{\mathrm{x}} \| \mathrm{R}_{\mathrm{x}}$ and $\mathrm{T}_{\mathrm{x}} \perp \mathrm{R}_{\mathrm{x}}$ measurements at $60 \mathrm{MHz}$. Otherwise, features and gray scale are the same as in Figures 6 and 8. Two pulse lengths, 1000 and $250 \mathrm{~ns}$, were used. From left to right, the antenna arrangement and pulse lengths for each image are (a) $\mathrm{T}_{\mathrm{x}} \| \mathrm{R}_{\mathrm{x}}$ and 1000 ns, (b) $\mathrm{T}_{\mathrm{x}} \| \mathrm{R}_{\mathrm{x}}$ and 250 ns, (c) $\mathrm{T}_{\mathrm{x}} \perp \mathrm{R}_{\mathrm{x}}$ and 1000 ns, and (d) $\mathrm{T}_{\mathrm{x}} \perp \mathrm{R}_{\mathrm{x}}$ and 250 ns.

\section{Causes of radio-wave polarization and scattering and their response to frequencies}

\section{Interpretation for the $179 \mathrm{MHz}$ data}

The $\mathrm{T}_{\mathrm{x}} \| \mathrm{R}_{\mathrm{x}}$ measurements at $179 \mathrm{MHz}$ strongly suggest features of anisotropic scattering boundaries because the angles between maxima and minima are about $90^{\circ}$. The features agree well with those from the earlier $T_{x} \| R_{x}$ experiments at Mizuho reported by Yoshida and others (1987), Fujita and Mae (1993) and Maeno and others (1995). Macroscopic dielectric permittivity tensor data from the ice core also suggest birefringence (Fujita and Mae, 1993). Neither the earlier nor the present data rule out the birefringence effect. This is because a large $P_{\mathrm{R}}$ appears in one of the two anticipated principal axes. This fact suggests that birefringence effects occur, but the signal is the weakest in one of the principal axes due to weak reflectivity in that orientation. In other words, birefringence alone cannot explain the major angle between the maxima and the minima, because anisotropic scattering boundaries are needed to explain this observation. We therefore conclude that, for the $179 \mathrm{MHz}$ radio wave, scattering boundaries have anisotropy as large as $10 \mathrm{~dB}$ on the power decibel scale. Considering the imperfect polarizing of the radio antennas, the real anisotropy should be larger. The principal axes are along the flowline and the transverse line. In addition, the orientations of the $P_{\mathrm{R}}$ minima in the $T_{x} \perp R_{x}$ measurements agree with theory (Fig. 4b). Because the evidence suggests that birefringence and anisotropic scattering boundaries have the same principal axes, orientations of the $P_{\mathrm{R}}$ minima in $\mathrm{T}_{\mathrm{x}} \perp \mathrm{R}_{\mathrm{x}}$ measurements do not contradict the birefringence theory. The features of the maxima and minima in Figure $7 \mathrm{~b}$ are consistent with theories of both birefringence in Figure $3 \mathrm{~b}$ and the anisotropic scattering boundaries in Figure $4 \mathrm{~b}$.

According to a two-frequency radar experiment at Mizuho, the dominant cause of radio-wave scattering is changes in permittivity and not changes in conductivity at all depths (Fujita and others, 1999). According to this constraint, radio-wave scattering can be caused by $P_{\mathrm{D}}$ and $P_{\mathrm{COF}}$ at $179 \mathrm{MHz}$. $C_{\mathrm{A}}$ scattering should not be a dominant mechanism at Mizuho at $179 \mathrm{MHz}$. Fujita and others (1999) also argued that the dominant cause of radio-wave scattering is $P_{\mathrm{COF}}$ at least at depths below about $700-900 \mathrm{~m}$. This is because the hydrostatic pressure and the transformation of air bubbles into clathrate hydrate crystals should reduce density fluctuations deep in the ice sheet. But the $P_{\mathrm{D}} / P_{\mathrm{COF}}$ boundary might be shallower if densification occurs more rapidly and if shearing is stronger at Mizuho. This is possible because Mizuho is located in a warmer and steeper region than dome summit regions (Fig. la). We also note that clathrate hydrate crystals cannot have any significant effect on the dielectric permittivity, due to its very small volume fraction, of the order of $3 \times 10^{-4}$ (e.g. Lipenkov, 2000).

In addition to supporting previous findings, this study finds (i) at depths below about $900 \mathrm{~m}$, the scattering is strongest along the transverse line; and (ii) at depths above about $750 \mathrm{~m}$, the scattering is strongest along the flowline. We suggest that $P_{\mathrm{COF}}$ is the only possible cause of the strong anisotropic scattering at depths below about $900 \mathrm{~m}$. $C_{\mathrm{A}}$ is ruled out based on results from the two-frequency experiments, and although $P_{\mathrm{D}}$ might cause anisotropic scattering, the depths are too great to allow any $P_{\mathrm{D}}$ mechanism to occur. Moreover, COF changes within a horizontal plane would naturally cause very strong anisotropy in the scattering boundaries. Figure $2 \mathrm{a}-\mathrm{c}$ are sketches of three typical examples of COF at Mizuho. If the COF changes from one to another within a short distance, the scattering boundaries would become essentially those of an anisotropic tensor. Indeed, such changes of COF occur in Vostok deep ice (Lipenkov and Barkov, 1998). We do not have ice-core COF data from $700 \mathrm{~m}$ to the base of the ice sheet at about $2000 \mathrm{~m}$; however, the vertical-girdle-type $\mathrm{COF}$ due to tensile strain, discovered in the shallower region of the Vostok deep ice core (Lipenkov and others, 1989), would be an important reference to deduce how the COF at Mizuho develops in deep regions. Indeed, COF of the $700 \mathrm{~m}$ Mizuho station core and $\mathrm{COF}$ of the shallow side of Vostok station core are very similar. Also, interpretations of the data are qualitatively the same (cf. Fujita and others, 1987; Lipenkov and others, 1989). Lipenkov and Barkov (1998) reported that, as they investigated deeper, there were two types of COFs, vertical-girdle and single-pole. Moreover, they discovered a 


\section{$179 \mathrm{MHz}, 350 \mathrm{~ns}, 180-250 \mathrm{~m}$}

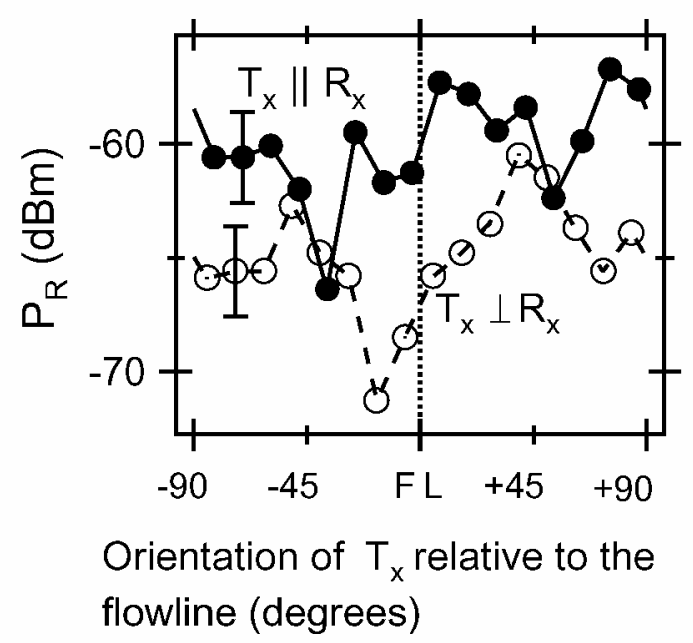

Fig. 10. Variation of $P_{\mathrm{R}}$ as a function of antenna orientation for $70 \mathrm{~m}$ thick depths between 180 and $250 \mathrm{~m}$. Frequency and pulse length are $179 \mathrm{MHz}$ and $350 \mathrm{~ns}$, respectively. Results from $\mathrm{T}_{\mathrm{x}} \| \mathrm{R}_{\mathrm{x}}$ measurement and $\mathrm{T}_{\mathrm{x}} \perp \mathrm{R}_{\mathrm{x}}$ measurement are given as solid circles and open circles, respectively. $P_{\mathrm{R}}$ was averaged over $70 \mathrm{~m}$ from the raw results. The error estimates are for the fluctuations due to the interference effect.

layered ice stratum composed of these two types of COFs. Their work is important evidence for COF in deep regions at Mizuho and also evidence of sharp changes of COFs in deep polar ice. We discuss this in detail further below. Thus, the facts that

(i) variations are due to permittivity changes,

(ii) depths are too great to allow any $P_{\mathrm{D}}$ mechanism to occur,

(iii) strongly anisotropic reflection boundaries are explained by the $P_{\mathrm{COF}}$ mechanism, and

(iv) layered strata composed of different COFs are known to exist

lead us to suggest that the major cause of the $179 \mathrm{MHz}$ radio scattering at depths below about $900 \mathrm{~m}$ at Mizuho is $P_{\mathrm{COF}}$.

The situation above about $750 \mathrm{~m}$ is different for several reasons. First, fact (ii) does not apply. Second, fact (iii) might apply, but if the $P_{\mathrm{D}}$ mechanism also causes some anisotropy, (iii) cannot apply only to $P_{\mathrm{COF}}$. In fact, it is well known that the depositional environment in Antarctica is highly anisotropic due to the prevailing wind, causing large sastrugi and dunes. Such depositional features might cause unknown anisotropic effects in the radio-wave scattering due to the $P_{\mathrm{D}}$ mechanism. For condition (iv), there seems to be no study that investigated fluctuations of the vertical-girdle-type $\mathrm{COF}$ on scales of millimeters to several meters. Therefore, our knowledge on the shallower scattering is that permittivity-based reflections have strong anisotropic features at Mizuho. We need more information to determine the relative contributions from $P_{\mathrm{D}}$ and $P_{\mathrm{COF}}$ mechanisms. To examine whether or not the $P_{\mathrm{D}}$ mechanism can cause anisotropic scattering boundaries due to a depositional environment related to sastrugi and dunes, one should examine the echoes from $250 \mathrm{~m}$ and above. This is because the shallowest echoes would likely come from density fluctuations, so one can check directly if echoes from the $P_{\mathrm{D}}$ zone have effects from anisotropic boundaries. Echoes from other mechanisms would be weaker. Indeed, Nakawo and Narita (1985) measured the density profile of the Mizuho station ice core. Above about $250 \mathrm{~m}$, density fluctuations were up to about $1 \mathrm{~kg} \mathrm{~m}^{-3}$. This fluctuation can produce a power reflection coefficient as large as about $-50 \mathrm{~dB}$. The power reflection coefficient from $P_{\mathrm{COF}}$ and $C_{\mathrm{A}}$ is generally well below $-60 \mathrm{~dB}$ (Fujita and Mae, 1994; Fujita and others, 2000). Figure 10 gives variation of $P_{\mathrm{R}}$ averaged over $70 \mathrm{~m}$ thick regions from depths of $180-250 \mathrm{~m}$, our shallowest data. The averaged $P_{\mathrm{R}}$ is shown as a function of antenna orientation for $T_{x} \| R_{x}$ and $T_{x} \perp R_{x}$ at $179 \mathrm{MHz}$. We emphasize here that signal variations are consistent with birefringence theory (Fig. 3) and no features suggest anisotropic scattering boundaries. Therefore, the data from the shallow $P_{\mathrm{D}}$ zone did not show effects from anisotropic depositional features. This fact suggests that the $P_{\mathrm{COF}}$ mechanism caused the strong scattering when the polarization plane was along the flowline at $179 \mathrm{MHz}$. This fact also suggests that there is a boundary between the shallow $P_{\mathrm{D}}$ zone and the $P_{\mathrm{COF}}$ zone at depths somewhere around $250 \mathrm{~m}$ at Mizuho.

\section{Relative contribution of the birefringence and the anisotropic scattering} boundary

The $\mathrm{T}_{\mathrm{x}} \| \mathrm{R}_{\mathrm{x}}$ measurements at $60 \mathrm{MHz}$ showed stronger features of birefringence, that is, the angle between the $P_{\mathrm{R}}$ maxima and minima is $45^{\circ}$ at most depth ranges, which is similar to the birefringence example in Figure 3. Also, the results do not have strong indications of anisotropic scattering boundaries (e.g. the superimposed $90^{\circ}$ component of angles between the large $P_{\mathrm{R}}$ and small $P_{\mathrm{R}}$ is weak except near $1000-1250 \mathrm{~m}$ ). The principal axes of birefringence are close to the flowline and the transverse line as before. The minima of the $T_{\mathrm{x}} \perp \mathrm{R}_{\mathrm{x}}$ measurements are also consistent with Figures $3 b$ and $4 b$.

The $60 \mathrm{MHz}$ data cannot be explained solely by birefringence, nor solely by anisotropic scattering. This is because, at depths of around $1000-1250 \mathrm{~m}$, the $P_{\mathrm{R}}$ signals for $T_{x} \| R_{x}$ still have a strong feature typical of anisotropic scattering boundaries. Indeed, in Figure $7 \mathrm{c}$, the difference in $P_{\mathrm{R}}$ maxima between the two principal axes is about 4$5 \mathrm{~dB}$. This feature cannot be explained by birefringence alone. Also, at depths of around $500-750 \mathrm{~m}$, the $P_{\mathrm{R}}$ signals for $T_{x} \| R_{x}$ still have large maxima at the flowline like those at $179 \mathrm{MHz}$. Therefore, both effects are necessary to explain the observed data at $60 \mathrm{MHz}$ even though the scattering boundaries are less anisotropic than those at $179 \mathrm{MHz}$.

To determine how $P_{\mathrm{D}}, C_{\mathrm{A}}$ and $P_{\mathrm{COF}}$ contribute to scattering at $60 \mathrm{MHz}$, we focus on the relative contributions from birefringence and anisotropic scattering boundaries. An observational fact is that birefringence apparently contributed to scattering at $60 \mathrm{MHz}$ but not at $179 \mathrm{MHz}$. We suggest that the $C_{\mathrm{A}}$ mechanism caused the dominant radio scattering at $60 \mathrm{MHz}$. The $C_{\mathrm{A}}$ mechanism is stronger at lower frequencies (Moore, 1988; Fujita and Mae, 1994; Fujita and others, 1999, 2000), whereas both $P_{\mathrm{D}}$ and $P_{\mathrm{COF}}$ mechanisms are independent of frequency. In addition, radio scattering caused by the $C_{\mathrm{A}}$ mechanism is largely isotropic; data have not shown strong anisotropy in the electrical conductivity of ice in the $\mathrm{MHz}$ range. In contrast, radio scattering caused by the $P_{\mathrm{COF}}$ mechanism is largely anisotropic.

In summary, at Mizuho at $179 \mathrm{MHz}$, the $P_{\mathrm{COF}}$ mechanism dominates below about $250 \mathrm{~m}$, causing a strong anisotropy in reflectivity. At depths shallower than about $250 \mathrm{~m}$, the $P_{\mathrm{D}}$ mechanism dominates. At $60 \mathrm{MHz}$, the contributions of $C_{\mathrm{A}}$ and $P_{\mathrm{COF}}$ are roughly equal. Therefore, the scattering 
boundaries are less anisotropic and effects from birefringence clearly appear. But $P_{\mathrm{COF}}$ gave stronger effects at depths near $1000-1250 \mathrm{~m}$. According to the two-frequency radar sounding along the traverse route, ice at depths near 1000-1250 m at Mizuho is a high shear zone that strongly illuminates the incident radio wave (see Fujita and others, 1999, plate 2e). The data here suggest that the strongest anisotropy due to $P_{\mathrm{COF}}$ occurs in the high shear zone where the $C_{\mathrm{A}}$ mechanism cannot dominate, even at $60 \mathrm{MHz}$.

\section{Variation of COF with depth}

\section{Crystal-orientation fabrics above $750 \mathrm{~m}$}

Our primary motivation here is to extract information about COF using the polarimetric radar sounding and to use the COF information to better understand the physical conditions in ice, particularly the ice-flow regime. We first infer the $\mathrm{COF}$ according to the strong scattering in the flowline orientation at depths more than about $750 \mathrm{~m}$. In the shallower ice, the $700 \mathrm{~m}$ Mizuho station ice core has the COF sketched in Figure $2 \mathrm{a}-\mathrm{c}$. The $c$ axes of the grains gradually concentrated on a vertical girdle with increasing depth. It is important to determine why strong scattering at $179 \mathrm{MHz}$ occurred only when the polarization plane was oriented along the flowline. A plausible explanation is that the cluster strength of the vertical-girdle fabric changes from one depth to another. In this case, major changes in the macroscopic dielectric permittivity tensor appear mainly along the symmetrical axis of the uniaxial tensor, that is, along the flowline. Viewed from the symmetrical axis, the development of a vertical-girdle-type fabric means that all of the $c$ axes move away from the symmetrical axis. The other two axes, the vertical axis and the transverse axis, are almost equivalent. Along each of these two axes, the macroscopic dielectric permittivity is always as large as that of a random fabric. Therefore, we deduce that the development of the vertical-girdle type significantly changes the dielectric permittivity tensor along the flowline axis, but it has little effect on the other two axes. No study has yet investigated fluctuations of verticalgirdle-type COF over scales of several millimeters to meters. We clearly need verification from ice cores like Mizuho or Vostok to better understand the mechanism that causes fluctuations of the vertical-girdle-type COF.

\section{Crystal-orientation fabrics at 750-900 m}

The stacking structure of COF at depths below about 750$900 \mathrm{~m}$ should be different from the upper vertical-girdle type. This is because the maxima of $P_{\mathrm{R}}$ in the $\mathrm{T}_{\mathrm{x}} \| \mathrm{R}_{\mathrm{x}}$ measurements are not clear. Also, at $700 \mathrm{~m}$, the COF already has a well-developed, vertical-girdle-type fabric in the ice core (Fujita and others, 1987). Thus, the vertical-girdle-type fabric cannot continue to develop because the crystal grains cannot rotate, even with greater tensile strain. Under such a welldeveloped vertical-girdle-type fabric, the deformation mechanism of ice is not basal glide motion of crystal dislocations. Instead, non-basal glide motion of dislocations, climb motion (Hondoh, 2000) and possibly recrystallization are necessary to cause further tensile strains. Moreover, Azuma's (1994) anisotropic flow law predicts that the strain rate of a well-developed vertical-girdle-type fabric is about 10 times smaller than that of isotropic ice. Therefore, ice with a welldeveloped vertical-girdle-type fabric is hard ice in which the orientation of each $c$ axis cannot change, even with greater tensile strain. The disappearance of anisotropy in the scatter- ing boundaries between 750 and $900 \mathrm{~m}$ (Fig. 9a) was likely caused by this saturation of basal-plane-motion-based tensile strain in ice. Thus, there should be well-developed, verticalgirdle-type fabrics at depths of 750-900 m.

\section{Crystal-orientation fabrics below about $900 \mathrm{~m}$}

Below about $900 \mathrm{~m}$, the maxima of $P_{\mathrm{R}}$ in the $\mathrm{T}_{\mathrm{x}} \| \mathrm{R}_{\mathrm{x}}$ measurements appear when the polarization planes are oriented in the transverse line. Thus, there should be changes of the dielectric permittivity tensor component in this axis. The vertical-girdle type alone cannot explain changes of the tensor in this orientation. Traverse radar measurements (antennas oriented only along the traverse line) near Mizuho station showed that the radio waves scattered strongly at these depths (Fujita and others, 1999). Considering that deeper ice generally has high shearing and that high shearing of ice produces a single-pole crystal fabric, layers with a single pole should occur. However, single-pole fabrics alone cannot cause anisotropic scattering because single poles have an isotropic dielectric permittivity tensor in the horizontal plane.

A basic property of the single-pole fabric under high shearing in the ice sheet is that initial small fluctuations of viscosity along depths are amplified by positive feedback into regions of highly strained ice and regions with little strain. That is, deformed ice becomes softer and deforms more readily, thus forming a stronger single-pole fabric than the surrounding ice (see, e.g., Paterson, 1991; Lipenkov and Barkov, 1998). Because strains in ice respond highly non-linearly to given stresses (e.g. the non-linearity in flow laws), this amplification should be strong. When high shear zones have such strong amplification, a strong single-pole fabric appears in several limited depth ranges (further details are in section 4.1.3 of Fujita and others, 1999). Several real examples including the high shear zones in deep regions of Vostok ice cores are discussed below. Considering this suggested basic nature of COF development, we suggest that only one scenario can explain all of the observational facts obtained in this study. As in the high shear zones of Vostok deep ice cores, ice is a layered ice stratum composed of both well-developed, vertical-girdle-type fabric as in Figure 2c, and single-pole fabric as in Figure 2d. Layers of single-pole COF have greater response to shear stress, whereas layers of vertical-girdle-type $\mathrm{COF}$ have greater response to stress from convergent ice flow than to shear stress. In this case, radio waves will scatter strongly only in the polarization plane of the transverse direction because the contrast between Figure 2c and d gives a contrast of the dielectric permittivity tensor only in the transverse direction. Such a contrast causes scattering anisotropy well above $10 \mathrm{~dB}$. It also gives a scattering coefficient as large as $-60 \mathrm{~dB}$ in power in orientations of maximum reflectivity (Fujita and Mae, 1994; Fujita and others, 2000). This value is extremely large as the scattering coefficient at the deeper side in polar ice sheets. We therefore suggest that, below about $900 \mathrm{~m}$ to the deepest limit of the $P_{\mathrm{COF}}$ zone at about $1500 \mathrm{~m}$, the ice has layers of vertical-girdle-type fabric stacked amongst layers of single-pole fabric.

\section{Abrupt changes of COFs in the Antarctic ice sheet}

\section{Four examples}

Because there is some debate about whether or not COF changes can occur over scales short enough to cause radar 
scattering, we describe below four reports of rapid COF changes in Antarctic ice.

The most common COF at Vostok is the vertical-girdle type associated with relatively coarse-grained interglacial ice, although single-pole fabric occurred in fine-grained glacial ice (Lipenkov and Barkov, 1998). Lipenkov and Barkov (1998) report that the difference between these two COFs is very small in the upper section of the ice sheet but increases with depth and is very clear below $2700 \mathrm{~m}$. Moreover, they found a layered ice stratum composed of these two types of COF at $3460-3538 \mathrm{~m}$. The thickness of the single-pole COF layers enclosed by vertical-girdle COF layers was of the order of several millimeters to several centimeters (Duval and others, 1998; personal communication from V. Ya. Lipenkov, 2002). This indicates that ice sheets characterized by vertical-girdle-type COF can have a stacking structure when subjected to high shearing deep in the ice.

Abrupt changes of COFs were also found in an ice core drilled at Dome F, a region without flow. Azuma and others (2000) discovered that the cluster strength of the $c$ axis around the vertical changed in many layers within the last glacial age (500-800 m) in the Dome F Antarctic ice core. In addition, N. Azuma (personal communication, 1999) used the newly invented automatic ice-fabric analyzer (Wang and Azuma, 1999) and found that the ice contains significant fluctuations of cluster strength, even in $1 \mathrm{~m}$ long cores. The "median inclination" (defined by Azuma and others, 2000) changed by as much as $10^{\circ}$ within a distance of several centimeters.

Gow and Williamson (1976) investigated the COF in a Byrd Station ice core and described six cloudy bands that contain visible volcanic-glass shards. Below $910 \mathrm{~m}$, the COF was more tightly clustered about the vertical in the cloudy bands than in the enclosing ice. The bands were $1-60 \mathrm{~mm}$ thick. Because the crystal sizes of such layers were always much smaller than those of the enclosing ice and had a fragmented appearance, they argued that such layers might constitute zones of actual shear displacement in the ice sheet. This is a valid example of sharp COF change, although COF changes in our data may be different from this example.

The last example is the study by Thwaites and others (1984). They investigated the relationship between borehole closure rate and COF in the ice cores from Cape Folger, Antarctica. Cape Folger is near the coastal margin of the ice sheet at Law Dome. The closure rate was highly dependent on depth and was closely related to the COF of the ice. The zones at which the non-uniform closure occurred were $0.5-3 \mathrm{~m}$ wide. This suggests that the COFs changed over scales of $0.5-3 \mathrm{~m}$.

The above four examples indicate that there are significant COF fluctuations under at least four conditions: (i) the dome summit at Dome F; (ii) flowing ice at Vostok, $250 \mathrm{~km}$ from an ice divide (ridge B); (iii) cloudy bands and enclosing ice in the Byrd Station ice; and (iv) Cape Folger ice near the coast. Until recently, measuring $\mathrm{COF}$ changes over sub-meter distances on deep ice cores has been too time-consuming, and thus, except for the above examples, direct evidence for abrupt COF changes remains weak. But with the new methods pioneered by Wang and Azuma (1999) and the indirect indications of abrupt COF changes in this study, this debate over abrupt COF changes should be resolved soon. The four examples given here are all for different conditions; thus, abrupt changes of COFs might be widespread in Antarctic ice.

Open question: mechanism causing the abrupt changes

Two examples of abrupt COF changes, that at Dome F and that deduced at Mizuho at depths above about $750 \mathrm{~m}$, cannot be explained by positive feedback between softening of the strained ice and simple shear strain. This is because stressstrain configuration at Dome F is not simple shear. It is more likely uniaxial compression or pure shear typical for a dome region and ice-divide zones. At Mizuho, the stress-strain configuration is uniaxial tension. In all three types of stressstrain configurations (uniaxial compression, pure shear and uniaxial tension), strain hardens the ice except for the initial $10-30 \%$ of the strain that softens ice (see anisotropic flow law and Azuma, 1994, fig. 5). At Dome F, the vertical compression is well above $10-30 \%$. Also, according to the strain-history analysis of a Mizuho station ice core (Fujita and others, 1987, fig. 7), the total tensile strain is $40-140 \%$ at about $100-700 \mathrm{~m}$. Therefore the initial strain softening cannot be a major reason for the contrasts of COFs in uniaxial strain. These facts imply an important feature of ice textures in polar ice sheets. That is, abrupt changes in simple shear are only a secondary, yet important, effect of ice flow. Before ice reaches depths at which it is subjected to simple shear, there is already some primary mechanism that produces initial abrupt COF changes. The primary mechanism seems to be related to several properties in ice, such as changes of impurity content typical for glacial-age/interglacial-age ice, grain-size and shape, or initial depositional environment (e.g. Paterson, 1991; Lipenkov and Barkov, 1998; Azuma and others, 2000). Based on our discussion of the shallow side of Mizuho, together with the observation for the Dome F ice, relations among these should be extensively investigated to understand the primary cause of $\mathrm{COF}$ changes.

\section{CONGLUDING REMARKS}

Based on our polarimetric radar experiments at Mizuho station, we suggest the following conclusions:

(1) At $179 \mathrm{MHz}$, radar signals are strongly controlled by anisotropic scattering boundaries with anisotropy as large as $10 \mathrm{~dB}$.

(2) At $179 \mathrm{MHz}$, the major cause of the radio scattering below about $250 \mathrm{~m}$ at Mizuho is $P_{\mathrm{COF}}$.

(3) At $60 \mathrm{MHz}$, the major causes of radio scattering at Mizuho are $P_{\mathrm{COF}}$ and $C_{\mathrm{A}}$. However, at high-shear zones, $P_{\mathrm{COF}}$ has the stronger influence.

(4) Between 250 and $750 \mathrm{~m}$, it is highly likely that the ice sheet has stacking of the vertical-girdle-type fabric with various cluster strengths. Between 750 and $900 \mathrm{~m}$, there is a zone of well-developed, vertical-girdle-type fabric.

(5) Below about $900 \mathrm{~m}$ and until the deepest limit of the $P_{\mathrm{COF}}$ zone, the ice has layers of vertical-girdle-type fabric stacked amongst layers of single-pole fabric as found previously in a Vostok deep ice core.

These conclusions and suggestions should significantly influence the understanding of ice dynamics and radarsounding techniques on ice sheets. However, important questions remain: (a) Why is this ice sheet composed of such a stacking structure, and how widespread are the structures? (b) How does such a stacking structure affect our understanding of ice dynamics, and how might it lead to better modeling? (c) What is the origin of the COF fluctuations, and how do they develop during ice flow from the dome summit to the coast? (d) Why does the fabric streng th 
vary/jump with depth in stress-strain configurations of uniaxial compression, pure shear, uniaxial tension, and without simple shear? To answer these questions, additional radar data are required, particularly from traverses along the ice flow and its transverse direction. We suggest that radar is, presently, the only way to investigate COF over wide regions in polar ice sheets. The experiments here are from a single site, but similar radar measurements over wider regions might provide invaluable information on the physical structure of polar ice sheets. We hope that the recent polarimetric radar sounding along several traverse routes by the 40th Japanese Antarctic Research Expedition (JARE) in 1999/2000 (Matsuoka and others, 2002) will provide some of the answers. Also, we expect that automatic fabric analyzers will provide many more datasets of continuous COF measurements along ice cores. By combining the radar data with ice-core data, we should be able to better understand the three-dimensional dynamical structure of polar ice sheets.

\section{ACKNOWLEDGEMENTS}

This paper is a contribution to the Dome Fuji Project, a program conducted by the Japanese Antarctic Research Expedition. We thank the science editor, T. Thorsteinsson, and three anonymous reviewers for their kind and critical review and for their efforts to improve the paper.

\section{REFERENGES}

Azuma, N. 1994. A flow law for anisotropic ice and its application to ice sheets. Earth Planet. Sci. Lett., 128(3-4), 601-614.

Azuma, N. and6 others. 2000. Crystallographic analysis of the Dome Fuji ice core. In Hondoh, T., ed. Physics of ice core records. Sapporo, Hokkaido University Press, 45-6l.

Bogorodsky, V.V., C. R. Bentley and P. E. Gudmandsen. 1985. Radioglaciology. Dordrecht, etc., D. Reidel Publishing Co.

Duval, P., V. Lipenkov, N. I. Barkov and S. de la Chapelle. 1998. Recrystallization and fabric development in the Vostok ice core. [Abstract.] Eos, 79(45), Fall Meeting Supplement, F152.

Fujita, S. and S. Mae. 1993. Relation between ice sheet internal radio-echo reflections and ice fabric at Mizuho station, Antarctica. Ann. Glaciol., 17, 269-275.

Fujita, S. and S. Mae. 1994. Causes and nature of ice-sheet radio-echo internal reflections estimated from the dielectric properties of ice. Ann. Glaciol., 20, 80-86.

Fujita, S., M. Nakawo and S. Mae. 1987. Orientation of the $700-\mathrm{m}$ Mizuho core and its strain history. Proc. NIPR Symp. Polar Meteorol. Glaciol. 1, 122-131.

Fujita, S., S. Mae and T. Matsuoka. 1993. Dielectric anisotropy in ice Ih at 9.7 GHz. Ann. Glaciol., 17, 276-280.

Fujita, S., K. Kawada and Y. Fujii. 1998. Glaciological data collected by the 37th Japanese Antarctic Research Expedition during 1996-1997. JARE Data Rep. 234. (Glaciology 27.)

Fujita, S. and6 others. 1999. Nature of radio-echolayering in the Antarctic ice sheet detected by a two-frequency experiment. F. Geophys. Res., 104(B6), 13,013-13,024.

Fujita, S., T. Matsuoka, T. Ishida, K. Matsuoka and S. Mae. 2000. A summary of the complex dielectric permittivity of ice in the megahertz range and its applications for radar sounding of polar ice sheets. In Hondoh, T., ed. Physics of ice core records. Sapporo, Hokkaido University Press, 185-212.
Fujita, S., H. Maeno, T. Furukawa and K. Matsuoka. 2002. Scattering of VHF radio waves from within the top $700 \mathrm{~m}$ of the Antarctic ice sheet and its relation to the depositional environment: a case-study along the Syowa-Mizuho-Dome Fuji traverse. Ann. Glaciol., 34, 157-164.

Gough, S. R. 1972. A low temperature dielectric cell and the permittivity of hexagonal ice to 2 K. Can. 7. Chem., 50(18), 3046-3051.

Gow, A. J. and T. Williamson. 1976. Rheological implications of the internal structure and crystal fabrics of the West Antarctic ice sheet as revealed by deep core drilling at Byrd station. Geol. Soc. Am. Bull., 87(12), 1665-1677.

Hargreaves, N. D. 1977. The polarization of radio signals in the radio echo sounding of ice sheets. F. Phys. D, 10(9), 1285-1304.

Harrison, G. H. 1973. Radio echo sounding of horizontal layers in ice. $\mathcal{f}$ Glaciol., 12(66), 383-397.

Higashi, A., M. Nakawo, H. Narita, Y. Fujii, F. Nishio and O. Watanabe. 1988. Preliminary results of analyses of $700 \mathrm{~m}$ ice cores retrieved at Mizuho station, Antarctica. Ann. Glaciol., 10, 52-56.

Hondoh, T. 2000. Nature and behavior of dislocations in ice. In Hondoh, T., ed. Physics of ice core records. Sapporo, Hokkaido University Press, 3-24.

Jacobel, R.W. and S. M. Hodge. 1995. Radar internal layers from the Greenland summit. Geophys. Res. Lett., 22(5), 587-590.

Langway, C. C., Jr. 1958. Ice fabrics and the universal stage. SIPRE Tech. Rep. 62.

Lipenkov, V. Ya. 2000. Air bubbles and air-hydrate crystals in the Vostok ice core. In Hondoh, T., ed. Physics of ice core records. Sapporo, Hokkaido University Press, 327-358

Lipenkov, V. Ya. and N. I. Barkov. 1998. Internal structure of the Antarctic ice sheet as revealed by deep core drilling at Vostok station [Stroyeniye Antarkticheskogo lednikovogo pokrova po rezul'tatam glubokogo bureniya na stantsii Vostok]. In Lake Vostok study: scientific objectives and technological requirements. International workshop. Abstracts. St Petersburg, Arctic and Antarctic Research Institute, 31-35.

Lipenkov, V. Ya., N. I. Barkov, P. Duval and P. Pimienta. 1989. Crystalline texture of the $2083 \mathrm{~m}$ ice core at Vostok station, Antarctica. F. Glaciol., 35(121), 392-398.

Maeno, H., S. Fujita, K. Kamiyama, H. Motoyama, T. Furukawa and S. Uratsuka. 1995. Relation between surface ice flow and anisotropic internal radio-echoes in the Antarctic ice sheet. Proc. NIPR Symp. Polar Meteorol. Glaciol. 9, 76-86.

Matsuoka, T., S. Fujita, S. Morishima and S. Mae. 1997. Precise measurement of dielectric anisotropy in ice Ih at $39 \mathrm{GHz}$. F. Appl. Phys., 81(5), 2344-2348

Matsuoka, K., H. Maeno, S. Uratsuka, S. Fujita, T. Furukawa and O. Watanabe. 2002 A ground-based, multi-frequency ice-penetrating radar system. Ann. Glaciol., 34, 171-176. (Erratum: Ann. Glaciol., 35, 591.)

Moore, J. C. 1988. Dielectric variability of a $130 \mathrm{~m}$ Antarctic ice core: implications for radar sounding. Ann. Glaciol., 11, 95-99.

Motoyama, H. and 8 others. 1995. Preliminary study of ice flow observations along traverse routes from coast to Dome Fuji, East Antarctica by differential GPS method. Antarct. Rec., 39, 94-98.

Nakawo, M. and H. Narita. 1985. Density profile of a $413.5 \mathrm{~m}$ deep fresh core recovered at Mizuho station, East Antarctica. Natl. Inst. Polar Res. Mem. Spec. Issue 39, 141-156.

Naruse, R. and H. Shimizu. 1978. Flow line of the ice sheet over Mizuho Plateau. Natl. Inst. Polar Res. Mem., Special Issue 7, 227-234.

Paterson, W. S. B. 1991. Why ice-age ice is sometimes "soft". Cold Reg. Sci. Technol., 20(1), 75-98.

Paterson, W. S. B. 1994. The physics of glaciers. Third edition. Oxford, etc., Elsevier.

Robin, G. de Q., S. Evans and J.T. Bailey. 1969. Interpretation of radio echo sounding in polar ice sheets. Philos. Trans. R. Soc. London, Ser. A, 265(1166), 437-505.

Thwaites, R. J., C. J. L. Wilson and A. P. McCray. 1984. Relationship between bore-hole closure and crystal fabrics in Antarctic ice core from Cape Folger. 7. Glaciol., 30 (105), 171-179.

Wang Yun and N. Azuma. 1999. A new automatic ice-fabric analyzer which uses image-analysis techniques. Ann. Glaciol., 29, 155-162.

Yoshida, M., K. Yamashita and S. Mae. 1987. Bottom topography and internal layers in East Dronning Maud Land, East Antarctica, from $179 \mathrm{MHz}$ radio echo-sounding. Ann. Glaciol., 9, 221-224. 